09

\title{
Исследование процессов фотодеградации бриллиантового зеленого на механоактивированных порошках оксида цинка
}

\author{
() Ш.А. Сюлейман, ${ }^{1}$ Н.Д. Якушова, ${ }^{2}$ И.А. Пронин, ${ }^{2,3}$ Н.В. Канева, ${ }^{1}$ А.С. Божинова, ${ }^{1}$ К.И. Папазова, ${ }^{1}$ \\ М.Н. Ганчева, ${ }^{4}$ Д.Ц. Димитров, ${ }^{1}$ И.А. Аверин, ${ }^{2}$ Е.И. Теруков, ${ }^{5}$ В.А. Мошников ${ }^{2,3}$ \\ ${ }^{1}$ Софиийский университет „Св. Климент Охридский“, \\ 1164 София, Болгария \\ ${ }^{2}$ Пензенский государственный университет, 440026 Пенза, Россия \\ ${ }^{3}$ Санкт-Петербургский государственный электротехнический университет „ЛЭТИ“ им. В.И. Ульянова (Ленина), \\ 197376 Санкт-Петербург, Россия \\ ${ }^{4}$ Болгарская академия наук, институт общей и неорганической химии, \\ 1113 София, Болгария \\ ${ }^{5}$ Физико-технический институт им. А.Ф. Иофрфе РАН, \\ 194021 Санкт-Петербург, Россия \\ e-mail: pronin_i90@mail.ru
}

(Поступило в Редакцию 13 февраля 2017 г.)

Проведено исследование фотокаталитической активности коммерческих и механоактивированных порошков оксида цинка на примере разложения бриллиантового зеленого. Целью работы явилось исследование влияния времени измельчения $(0,1,3,5,7 \mathrm{~min})$ на структуру оксида цинка и его фотокаталитическую активность в видимом и ультрафиолетовом (УФ) излучении. Установлено, что при использовании УФ излучения константа скорости окисления красителя для образцов, активированных в течение $1 \mathrm{~min}$, возрастает по сравнению с неактивированными порошками, а дальнейшая механоактивация, напротив, приводит к уменьшению фотокаталитиекой активности. При использовании видимого излучения минимальную фотокаталитичекую активность показали образцы, активированные в течение $1 \mathrm{~min}$, а дальнейшая механоактивация приводила к повышению эффективности процесса фотокатализа.

DOI: 10.21883/JTF.2017.11.45134.2202

\section{Введение}

Использование полупроводникового оксида цинка для фотокаталитического разложения веществ, загрязняющих воздух и воду, является перспективным подходом для эффективной очистки окружающей среды $[1,2]$. Из литературных данных известна высокая эффективность использования $\mathrm{ZnO}$ для разложения активных красителей [3], фенола [4], хлорфенола [5] и других загрязняющих веществ [6,7]. Также материалы на основе оксида цинка широко используются при создании газовых сенсоров, где путем целенаправленного модифицирования каталитических центров на поверхности можно добиваться повышения значении газочувствительности [8,9]. Также большое количество работ посвящено исследованию влияния различных способов модификации (легирование полупроводниками, металлами и неметаллами $[10,11])$ на каталитические свойства материалов на основе $\mathrm{ZnO}$. Однако помимо химического модифицирования в настоящее время широкое распространение получает использование механического высокоэнергетического размола [12] - простого, эффективного и производительного способа подготовки наноструктурированных фотокаталитических материалов.

Механический высокоэнергетический размол - это типичный пример нанотехнологий типа „сверху-вниз“ („top-down“), в результате которого нанокристалличе- ский порошок формируется размалыванием крупнозернистой структуры в результате интенсивных пластических деформаций в планетарных, шаровых или вибрационных мельницах. Следует отметить, что вследствие релаксации поля напряжений в твердом теле после механических воздействий будут меняться не только размеры зерен материала, но и их физико-химические свойства [13]. Среди основных каналов релаксации поля напряжений выделяют образование новой поверхности и формирование дефектов кристаллической структуры, а также их выход на поверхность зерен. По всей видимости, именно канал релаксации, связанный с появлением дефектов, является причиной повышения реакционной и каталитической активности материалов, полученных механическим высокоэнергетическим размолом [14]. Тем не менее, несмотря на многочисленные достижения в области механоактивации наноматериалов, понимание неравновесных механохимических процессов еще далеко до завершения $[15,16]$.

Настоящая работа посвящена исследованию фотокаталитической активности коммерческих и механоактивированных порошков оксида цинка. Целью работы явилось исследование влияния условий измельчения на структуру и фотокаталитическую активность $\mathrm{ZnO}$. Фотокаталитическая активность образцов исследовалась в видимом и ультрафиолетовом свете с использованием модельного загрязнителя бриллиантового зеленого (ис- 
пользуется в качестве антисептического лекарственного средства, красителя, для окрашивания клеточных сред и др.).

\section{1. Эксперимент}

\section{1. Материалы и реагенты}

Для получения механоактивированных порошков оксида цинка использовался коммерческий порошок $\mathrm{ZnO}$ (> 99.0\%, Acros Organics, США).

В качестве модельного загрязнителя был выбран краситель бриллиантовый зеленый $\mathrm{C}_{29} \mathrm{H}_{34} \mathrm{O}_{4} \mathrm{~N}_{2}$ (Acros Organics, США).

\section{2. Подготовка и исследование образцов}

Коммерческие порошки $\mathrm{ZnO}$ были подвергнуты интенсивной механической обработке в планетарной шаровой мельнице Planetary Micro Mill PULVERISETTE 7 premium line в воздушной атмосфере. В процессе измельчения использовались следующие параметры:

- шары из нержавеющей стали диаметром $5 \mathrm{~mm}$,

- скорость измельчения в размольных барабанах $250 \min ^{-1}$,

- соотношение массы порошка и шаров - 10:1,

- время измельчения - 1, 3, 5 и $7 \mathrm{~min}$.

Фотокаталитические свойства коммерческих и механоактивированных порошков $\mathrm{ZnO}$ были исследованы при освещении ультрафиолетовым и видимым светом растворов красителя концентрацией $20 \mathrm{ppm}$. При этом загрузка катализатора составляла $0.5 \mathrm{~g} / \mathrm{cm}^{3}$, объем раствора - $250 \mathrm{ml}$. Источники излучения располагались следующим образом: УФ лампа Sylvania 18W BLB T8 (диапазон излучения 315-400 nm) размещалась на $10 \mathrm{~cm}$ выше поверхности раствора; линейная лампа Tungsram 500 W K1R7s 9700 Lm (максимум излучения на длине волны $700 \mathrm{~nm}$ ) для облучения видимым светом размещалась на $25 \mathrm{~cm}$ выше поверхности раствора. После приготовления растворов в них добавлялись исследуемые порошки $\mathrm{ZnO}$ с дальнейшим перемешиванием в течение $30 \mathrm{~min}$ в темноте до образования однородной суспензии. В процессе проведения фотокаталитических тестов из растворов через равные промежутки времени забирались пробы объемом $2 \mathrm{ml}$, которые после центрифугирования и фильтрования анализировались с помощью спектрофотометра Evolution 300 Thermo Scientific на длине волны, соответствующей максимальному поглощению красителя $(625 \mathrm{~nm})$. После проведения измерений пробы возвращались обратно в раствор. Во все время проведения эксперимента раствор перемешивался с помощью магнитной мешалки со скоростью вращения $400 \mathrm{~min}^{-1}$.

Морфология образцов исследовалась с помощью сканирующего электронного микроскопа JEOL JSM-5510; удельная площадь поверхности определялась по низкотемпературной сорбции азота методом Брюнера-Эммета-Теллера (БЭТ); кристаллическая структура порошков определялась с помощью рентгеновского дифрактометра Siemens D 500, используя $\mathrm{Cu} K_{\alpha}$-излучение в диапазоне $30<2 \Theta<80^{\circ}$ с шагом $2 \Theta=0.03^{\circ}$; данные по размеру кристаллитов, микронапряжений и параметров решетки были получены по методу Ритвельда [17].

\section{2. Результаты и обсуждение}

\section{1. Структура и фазовый состав фотокатализаторов}

На рис. 1 представлена морфология коммерческих образцов $\mathrm{ZnO}(a)$ и образцов после механоактивации в течение $7 \mathrm{~min}(b)$, полученная с помощью растрового электронного микроскопа.

Из рисунка видно, что коммерческие порошки ZnO coстоят из неоднородных зерен, размер которых находится в диапазоне $0.2-1 \mu \mathrm{m}$. Механоактивация образцов в течение $7 \mathrm{~min}$ делает порошок более однородным, размер кристаллитов составляет $0.2-0.5 \mu \mathrm{m}$ (с преобладанием размеров $\sim 0.5 \mu \mathrm{m})$.
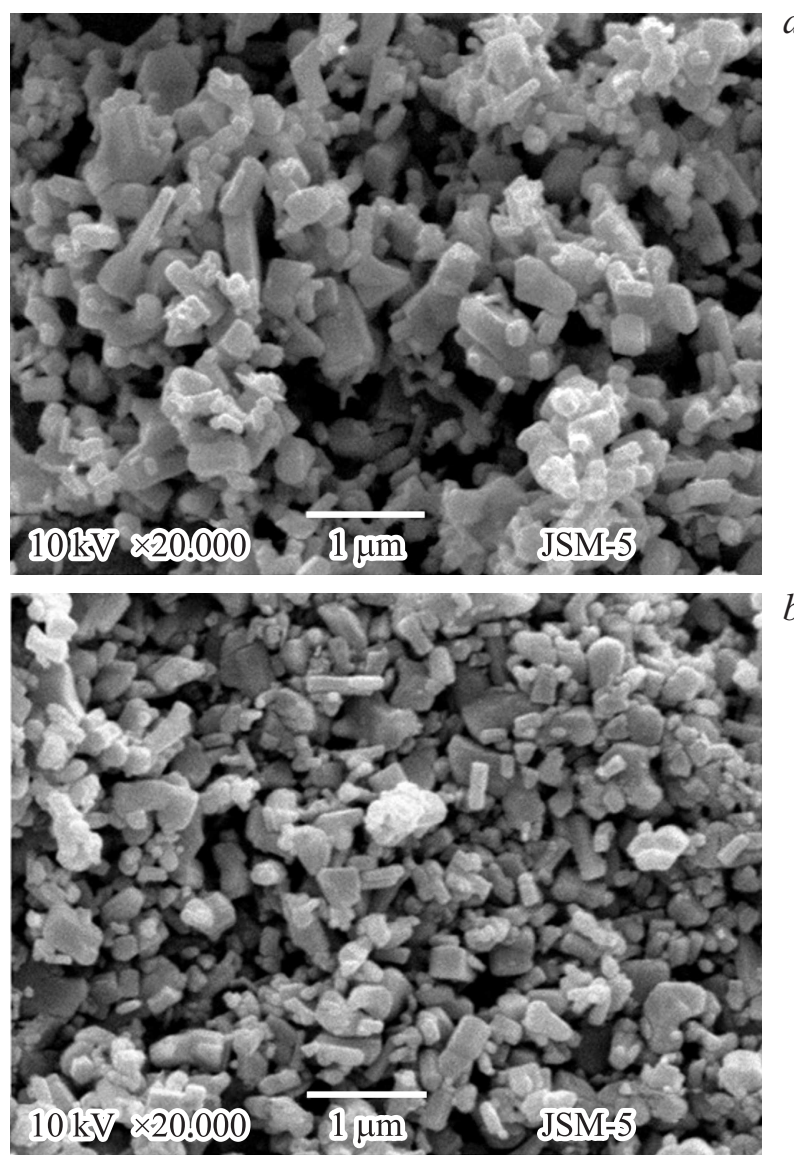

Рис. 1. Морфология поверхности порошков $\mathrm{ZnO}: a-$ коммерческого, $b-$ механоактивированного в течение $7 \mathrm{~min}$. 
Параметры полученных образцов

\begin{tabular}{c|c|c|c|c|c}
\hline \multirow{2}{*}{ Образец } & \multirow{2}{*}{$S_{\mathrm{BET}}, \mathrm{m}^{2} / \mathrm{g}$} & $d, \mathrm{~nm}$ & $\varepsilon \cdot 10^{4}$ & \multicolumn{2}{|c}{$k, \min ^{-1}$} \\
\cline { 4 - 5 } & & & & УФ излучение & Видимое излучение \\
\hline $\mathrm{ZnO}$ & 4.5 & 48 & 11 & 0.0558 & 0.0208 \\
$\mathrm{ZnO} \mathrm{1} \mathrm{min}$ & 4.6 & 46 & 12 & 0.0644 & 0.0159 \\
$\mathrm{ZnO} \mathrm{3} \mathrm{min}$ & 4.7 & 44 & 12 & 0.0366 & 0.0201 \\
ZnO 5 min & 4.7 & 44 & 12 & 0.0214 & 0.0236 \\
ZnO 7 min & 4.8 & 44 & 12 & 0.0221 & 0.0208
\end{tabular}

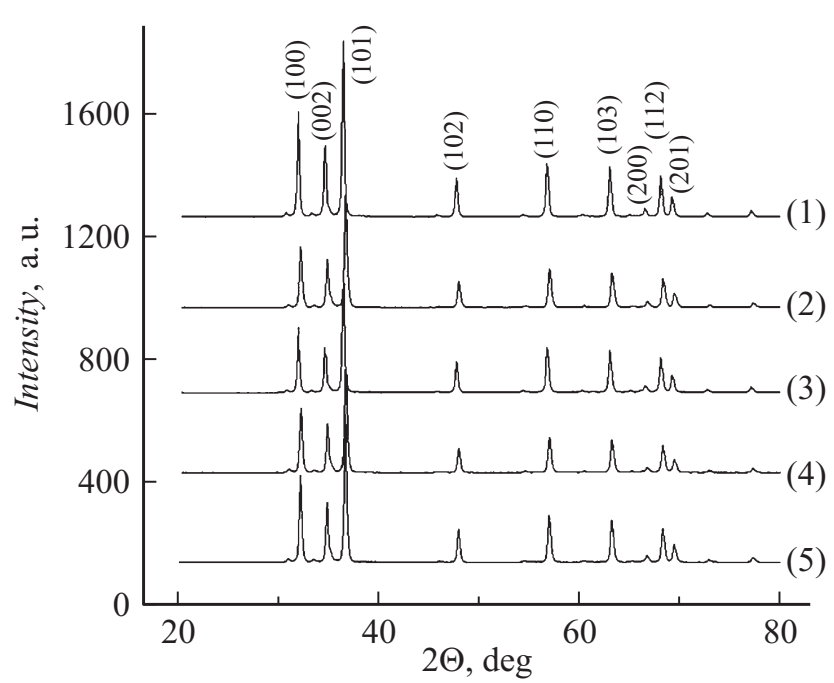

Pис. 2. Дифрактограммы образцов.

В таблице представлены значения удельной площади поверхности всех образцов, полученные методом низкотемпературной сорбции азота по теории БЭТ $\left(S_{\mathrm{BET}}\right)$. Как видно, измельчение в течение $7 \mathrm{~min}$ приводит к небольшому уменьшению удельной площади поверхности с 4.5 до $4.8 \mathrm{~m}^{2} / \mathrm{g}(6.7 \%)$.

На рис. 2 представлены рентгеновские дифрактограммы образцов ZnO. Иx анализ показывает, что материал имеет гексагональную структуру типа вюрцит (наличие рефлексов от семейств плоскостей (100), (002), (101), (102), (110), (103), (200), (112), (201)). Визуально рефлексы, отвечающие одному и тому же семейству плоскостей, для всех образцов имеют одинаковые интенсивности и уширения. В таблице представлены полученные на основе количественного анализа дифрактограмм данные по размерам кристаллитов $d$ и микронапряжениям в решетке $\varepsilon$.

Размер кристаллитов всех образцов находится в диапазоне $44-48 \mathrm{~nm}$ и незначительно уменьшается в процессе механоактивации. Микронапряжения $\varepsilon$ в кристаллической решетке исходных образцов $\mathrm{ZnO}$ составляли $1.1 \cdot 10^{-3}$, после механоактивации в течение $1 \mathrm{~min}$ увеличивались до $1.2 \cdot 10^{-3}$ и практически не менялись при дальнейшей обработке.
Bсе полученные образцы были испытаны на фотокаталитическую активность. Кинетические кривые фотокаталитического окисления бриллиантового зеленого в ультрафиолетовом и видимом излучениях приведены на рис. 3. Анализ рисунка показывает, что процессы фотодеградации бриллиантового зеленого близки к реакции псевдопервого порядка, поэтому кинетика фотокаталитического процесса приближенно описывается уравнением $\ln \left(C / C_{0}\right)=-k t$, где $C_{0}-$ начальная концентрация красителя, $C-$ концентрация красителя в момент времени $t, k-$ константа скорости реакции.

Схема процессов фотодеградации бриллиантового зеленого в ультрафиолетовом излучении представлена на рис. 4 [18]. На первом этапе полупроводник поглощает фотон с энергией $h v$, превышающей ширину запрещенной зоны $\mathrm{ZnO}\left(\Delta E_{g} \sim 3.36 \mathrm{eV}\right)$, что приводит к генерации электронно-дырочной пары. На втором этапе происходят процессы диффузии сгенерированных
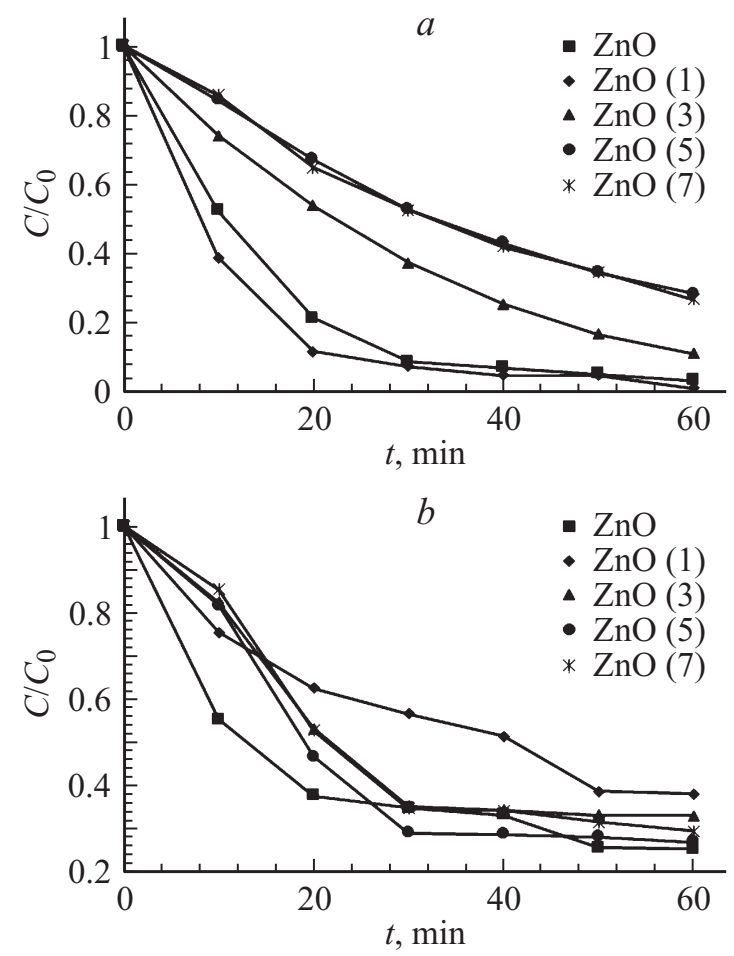

Рис. 3. Кинетические кривые фотокаталитического окисления бриллиантового зеленого в ультрафиолетовом $(a)$ и видимом $(b)$ излучении. 


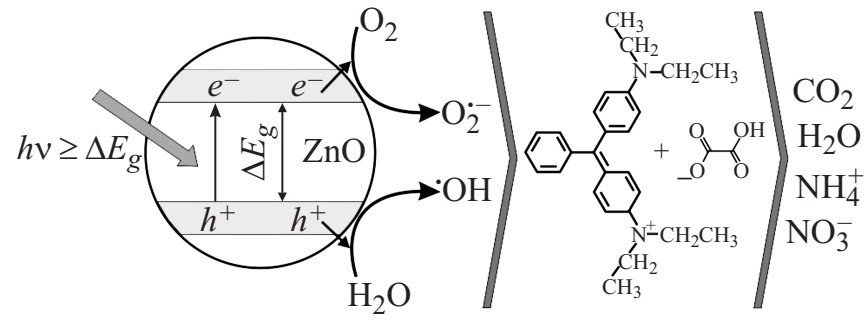

Рис. 4. Схема процессов фотодеградации бриллиантового зеленого в УФ излучении.

носителей к поверхности кристаллита, при этом часть их рекомбинирует в объеме полупроводника и на самой поверхности, что уменьшает квантовый выход фотокаталитического процесса. На третьем этапе возможны реакции свободных электрона и дырки с адсорбированными на поверхности частиц оксида цинка воды и молекулярного кислорода, приводящие к образованию гидроксильного радикала •ОН и супероксид-радикала $\mathrm{O}_{2}^{\bullet-}$ (следует отметить, что дно зоны проводимости $\mathrm{ZnO} C B$ лежит выше уровня редокс-потенциала реакции $\mathrm{O}_{2} / \mathrm{O}_{2}^{\bullet-}$, а потолок валентной зоны $V B$ расположен ниже уровня редокс-потенциала реакции $\mathrm{H}_{2} \mathrm{O} /{ }^{\bullet} \mathrm{OH}$, что термодинамически не запрещает появление данных радикалов):

$$
\begin{gathered}
\mathrm{O}_{2}+e^{-} \rightarrow \mathrm{O}_{2}^{\bullet-}, \\
\mathrm{H}_{2} \mathrm{O}+h^{+} \rightarrow \bullet \mathrm{OH}+\mathrm{H}^{+} .
\end{gathered}
$$

Полученные радикалы обладают высокой активностью и вступают в реакцию с бриллиантовым зеленым с образованием промежуточных соединений, продуктами разложения которых являются неорганические ионы и соединения: $\mathrm{CO}_{2}, \mathrm{H}_{2} \mathrm{O}, \mathrm{NH}_{4}^{+}, \mathrm{NO}_{3}^{-}$.

В случае использования для реакции фотодеградации бриллиантового зеленого видимого излучения ситуация несколько меняется. Фундаментального поглощения в данном случае наблюдаться не будет, поскольку длина волны излучения меньше ширины запрещенной зоны. Образование свободных электронов и дырок будет происходить только, вероятно, за счет фотовозбуждения носителей заряда с примесных уровней и уровней собственных электрически активных дефектов, которые всегда будут присутствовать в материале в малых концентрациях, так как они термодинамически равновесны [19]. Дальнейшие процессы фотодеградации в видимом излучении будут происходить аналогично фотодеградации в ультрафиолетовом свете.

На основании кинетических кривых фотокаталитического окисления, показанных на рис. 3, были рассчитаны зависимости константы скорости фотокаталитического разложения бриллиантового зеленого в видимом и ультрафиолетовом излучениях от времени механоактивации образцов $t_{\text {мA }}$ - рис. 5 .

Очевидно, что результатом обработки коммерческих порошков оксида цинка в планетарной мельнице является уменьшение среднего размера зерен и, как следствие, увеличение площади контакта порошков с молекулами красителя, что должно приводить к увеличению фотокаталитической активности материала. Тем не менее это не всегда так, поскольку при интенсивной механообработке увеличивается концентрация собственных точечных дефектов, выступающих в качестве центров рекомбинации. В $\mathrm{ZnO}$ существует большое количество типов точечных дефектов, таких как вакансии в подрешетке кислорода, вакансии в подрешетке цинка, междоузельный кислород и цинк, антиструктурные замещения. Общепринятым является тот факт, что основной тип собственных точечных электрически активных дефектов в $\mathrm{ZnO}$ при низких парциальных давлениях кислорода это двукратно ионизированные вакансии в подрешетке кислорода $V_{\mathrm{O}}^{\bullet \bullet}$, благодаря которым материал обязан существенной электропроводностью при низких температурах [20].

Из рис. 5 видно, что в случае использования УФ излучения константа скорости при механоактивации образца в течение $1 \mathrm{~min}$ возрастает, что может быть связано с увеличением удельной площади поверхности образца и довольно малой концентрацией дефектов. Однако при дальнейшем увеличении времени механоактивации константа скорости уменьшается, что связано с подавлением фотокаталитической активности из-за рекомбинации носителей заряда на образовавшихся дефектах. В этом

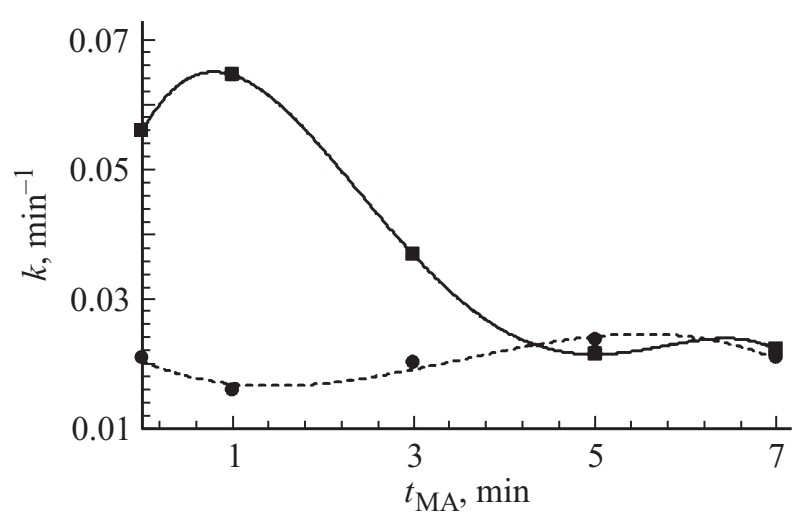

Рис. 5. Зависимость константы скорости фотокаталитического разложения бриллиантового зеленого в видимом (кружки) и ультрафиолетовом (квадраты) излучении от времени механоактивации образцов. $a$

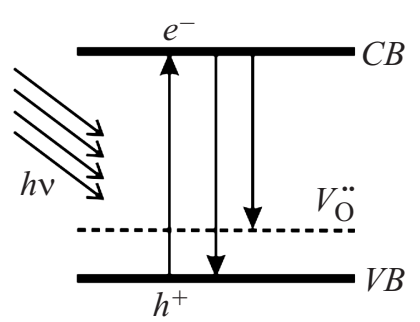

$b$

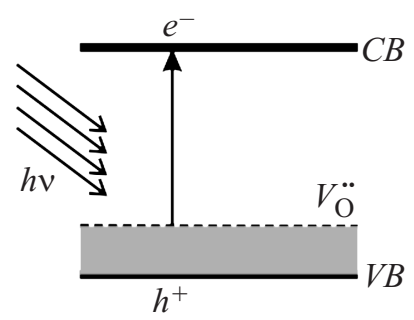

Рис. 6. Иллюстрация влияния вакансий в подрешетке кислорода в $\mathrm{ZnO}$ на фотокаталитические свойства. 
случае дальнейшее увеличение площади поверхности нивелируется возникающими рекомбинационными процессами.

Константа скорости реакции в видимом свете у коммерческих образцов будет существенно ниже, чем в ультрафиолете, из-за описанных выше причин. При механоактивации образца в течение 1 min будет наблюдаться уменьшение константы скорости за счет появления новых центров рекомбинации (рис. $6, a$ ).

Однако при дальнейшей обработке в планетарной мельнице концентрация кислородных вакансий начнет увеличиваться, что в конечном итоге приводит к появлению окраски материала и перекрытию примесных уровней с валентной зоной и смещению края фундаментального поглощения в длинноволновую область [21] рис. $6, b$. Последнее способствует расширению области полезного спектра, несмотря на введение дополнительных центров рекомбинации, и увеличению константы скорости.

\section{Выводы}

Таким образом, процессы механоактивации порошков оксида цинка приводят к возникновению различных явлений, которые могут диаметрально противоположно влиять на фотокаталитическую активность материала: увеличение площади поверхности, возникновение новых центров рекомбинации, фотовозбуждение носителей заряда с примесных уровней, красное смещение края поглощения и др. В зависимости от конкретных условий механоактивации и проведения эксперимента тот или иной фактор может стать доминирующим и вносить основной вклад в процессы фотокатализа, что необходимо учитывать при разработке новых фотокаталитических материалов.

Авторы из Болгарии выполняли свою часть работы при финансовой поддержке гранта ДФНИ-Т02/16.

Работа авторов из России выполнялась при финансовой поддержке Министерства образования и науки РФ (проект 16.897.2017/ПЧ) и РФФИ в рамках научной стажировки (проект № 16-33-50259 мол_нр).

\section{Список литературы}

[1] Козлова Е.А., Ремпель А.А., Валеева А.А., Горбунова Т.И., Кожевникова Н.С., Черепанова С.В., Герасимов Е.Ю., Сараев А.А., Коровин Е.Ю., Пармон В.Н. // Кинетика и катализ. 2015. Т. 56, № 4. С. 521.

[2] Qu X., Alvarez P., Li Q. // Water Research. 2013. Vol. 47. P. 3931.

[3] Behnajady M., Modishahla N., Hamzavi R. // J. Hazard. Mater., 2006. Vol. 133. P. 226

[4] Lathasree S., Rao A.N., Siva-Sankar B., Sadasivam B., Rengaraj K. // J. Mol. Catal. A: Chem. 2004. Vol. 223. P. 104.

[5] Pardeshi S., Patil A. // Solar Energy. 2008. Vol. 62. P. 700.
[6] Воронцов А.В., Козлов Д.В., Смирниотис П.Г., Пармон В.Н. // Кинетика и катализ. 2005. Т. 46. № 2. С. 203.

[7] Пронин И.А., Канева Н.В., Божинова А.С., Аверин И.А., Папазова К.И., Димитров Д.Ц., Мошников В.А. // Кинетика и катализ. 2014. Т. 55. № 2. С. 176.

[8] Pronin I.A., Dimitrov D.Tz., Krasteva L.K., Papazova K.I., Averin I.A., Chanachev A.S., Bojinova A.S., Georgieva A.Ts., Yakushova N.D., Moshnikov V.A. // Sens. Actuators, A. 2014. Vol. 206. P. 88.

[9] Dimitrov D.Tz., Nikolaev N.K., Papazova K.I., Krasteva L.K., Pronin I.A., Averin I.A., Bojinova A.S., Georgieva A.Ts., Yakushova N.D., Peshkova T.V., Karmanov A.A., Kaneva N.V., Moshnikov V.A. // Appl. Surf. Sci. 2017. Vol. 392. P. 95.

[10] Пронин И.А., Донкова Б.В., Димитров Д.Ц., Аверин И.А., Пенчева Ж.А., Мошников В.А. // ФТП. 2014. Т. 48. № 7. C. 868 .

[11] Ullah R., Dutta J. // J. Hazard. Mater. 2008. Vol. 156. P. 194.

[12] Гусев А.И. // Наноматериалы, наноструктуры, нанотехнологии. М.: Физматлит, 2007.

[13] Молчанов В.В., Буянов Р.А. // Успехи химии. 2000. Т. 69. № S. C. 476.

[14] Аввакумов Е.Г. // Механохимические методы активации химических процессов. Новосибирск: Наука, 1986.

[15] Sepelak V., Duvel A., Wilkening M., Becker K.D., Heitjans P. // Chem. Soc. Rev. 2013. Vol. 42. P. 7507.

[16] Русанов А.И. // Термодинамические основы механохимии. СПб.: Наука, 2006.

[17] Rietveld H.M. // J. Appl. Cryst. 1969. N 2. P. 65.

[18] Moshfegh A.Z. // J. Phys. D: Appl. Phys. 2009. Vol. 42. P. 233001.

[19] Samadi M., Zirak M., Naseri A., Khorashadizade E., Moshfegh A.Z. // Thin Solid Films. 2016. Vol. 605. P. 2.

[20] Fierro J.L.G. Metal Oxides: Chemistry and Applications. Boca Raton, FL: Taylor \& Francis Group, 2006.

[21] Wang J., Wang Z., Huang B., Ma Y., Liu Y., Qin X., Zhang X., Dai Y. // ACS Appl. Mater. Interfaces. 2012. Vol. 4. P. 4024. 